Article

\title{
Sustainability in Online Video Hosting Services: The Effects of Serendipity and Flow Experience on Prolonged Usage Time
}

\author{
Hsi-Peng Lu and Yi-Hsiu Cheng *(D) \\ Department of Information Management, National Taiwan University of Science and Technology, Taipei 10607, \\ Taiwan; lu@mail.ntust.edu.tw \\ * Correspondence: yhcheng@sce.pccu.edu.tw
}

Received: 26 December 2019; Accepted: 7 February 2020; Published: 10 February 2020

check for updates

\begin{abstract}
Online video hosting services have been a highly competitive e-commerce application in recent years. The service providers constantly seek viable ways for users to prolong usage time as a model for sustainable business development. In this study, we propose a framework to verify the impact of perceived serendipity on flow experience and prolong usage time. In addition, we verify the factors of online video platforms that affect perceived serendipity, such as enabled connections, introduced unexpected information, and induced curiosity. This study used questionnaires to survey YouTube users and analyzed 405 samples using the Structural Equation Model (SEM) method. The result shows that enabled connections and introduced unexpected information significantly affect perceived serendipity, which significantly impacts on the flow experience. Although induced curiosity does not significantly affect perceived serendipity, it directly affects the flow experience. Moreover, both perceived serendipity and flow experience positively affect intentions to prolong usage time. The results validate that serendipity is another antecedent of flow experience, and support the assumption that increasing the likelihood of perceived serendipity will affect users' intention to prolong usage time in online video hosting services. The implication of research and discussions provides references for online video hosting service providers in marketing and operations.
\end{abstract}

Keywords: flow experience; serendipity; prolong usage time; hyperlink; online video hosting service

\section{Introduction}

Sustainability is becoming an essential consideration in online video hosting services. In the digital age, according to attention economics, users' limited time and attention are scarce resources [1]. Traditionally, the scarce resources discussed in economics are raw materials. However, in the digital age, as the cost of copying information approaches zero, the enterprises that provide digital products are fighting for demand-side usage needs. The more demand there is, the more economies of scale can be achieved. In other words, if a company can grasp the user's attention and time in a digital environment, it will also have the ability to control the resources of the digital era. For the operators of a online platform, attracting users' attention and extending the use time on the platform can increase the users' stickiness to the platform, and it also means that the platform can increase profits from it [2]. Regardless of whether the platform is drawing advertising revenue or user word-of-mouth recommendations, the ability to attract users has an essential impact on the sustainability of online platform operations [3].

With the development of network media, online video services have gradually replaced traditional media, such as TV and movies, as the main channel of entertainment. If time is a valuable resource, then the operators of online video hosting services should try to prolong the usage time of users. 
In addition to obtaining users' limited time and attention resources, they can collect more user data for analysis and develop accurate predictions of user preferences. However, a massive increase of videos stored in online video platforms often makes users feel overwhelmed during selection. Therefore, online video platforms provide search and personalized recommendation functions to reduce search costs. Although personalized recommendations through an algorithm improve accuracy in conforming to users' interests, they reduce the possibility of bringing surprises to users that are expecting to see novelty content [4].

From a business ecosystem perspective, diversity also has a positive impact on the sustainable operation of online video platforms. In a robust business ecosystem, the diversity of suppliers can allow the ecosystem to maintain good development [5]. Following the same concept, an online video platform which provides users with diverse and heterogeneous video resources can also make the platform well developed. For users, such a platform offers a wide range of heterogeneous videos so users can have more choices during the browsing process, and can even generate many unexpected discoveries from the process. This means that when users continue to use the online video platform, they are not limited to watching similar types of videos, but instead have the opportunity to access more different kinds of resources. In other words, when browsing online video and audio platforms, users will not always be recommended similar videos by the platforms, but instead will have more opportunity to access different types of resources. the audio and video platforms can therefore stimulate the curiosity of users, and users are willing to extend their time watching videos on the platform. The user's stickiness to the platform will increase, which will also have a positive impact on the sustainable development of the audio and video platforms.

We think that the traditional "time-saving" website structures allow users to quickly and easily find the information they want to see. However, when users browse online video platforms, they are mostly entertainment-oriented and wish to have fun in the browsing process. Therefore, unlike the "time-saving" structure, to increase the stickiness of the platform, we believe that online video hosting services must be able to "kill time." In other words, it makes users discover unexpected and interesting content during their browsing, which can attract more attention, immerse themselves in the hyperlinks, and extend their usage time. This provides another direction for designing a sustainable digital content arrangement for online video hosting services.

Previous studies on information-seeking behavior have found that the serendipitous discovery of information is different from purposeful information seeking. Finding useful or exciting information by accident often brings a pleasant experience to users, and it affects usage willingness [6]. If users have serendipities while browsing, this may be another way to attract users and to prolong their usage time of online video platforms. Therefore, we will focus on how to stimulate serendipities and explore the impact of serendipities on prolonging the usage of online video hosting services. One of the research topics in this study is how the functions provided by the online video platform can cause users to have serendipities.

Prolonged usage means that users might increase their attachment to services, as the services grab users' attention and encourage them to immerse themselves in online activities. Users might lose their sense of the passage of time, as they live in the moment during online activities. In this state of mind, time seems to fall away. This state is referred to as "flow." According to flow theory [7], flow is a subjective state where people fully participate in an activity and forget the passage of time, fatigue, and all other things. Previous studies in the information field on flow have mainly focused on skill and challenge, particularly regarding computer uses, such as online shopping, social networking, and online gaming [8-12]. These studies considered factors that influenced users' sense of being as a flow experience, such as skill, challenge, interactivity, ease of use, and involvement. The importance of the flow theory is that the optimal experience is when the user enters the flow state. Hoffman and Novak [9] suggested that optimal experience can contribute to the success of online marketers by creating exciting experiences for users. Because the Internet is an interactive environment, it provides 
opportunities for users to experience flow during their navigation. Flow experience is a desirable marketing outcome of online interaction between users and firms.

However, past studies on flow experience in the information field failed to discuss that serendipity may also lead to the flow phenomenon. The research on users' web browsing behaviors indicated that online activities, such as browsing web pages, online shopping, and social media, really make users have flow experiences [13-15]. Information encountering, i.e., serendipity, often occur in the process of web browsing. Foster and Ford [16] regarded serendipity as an important by-product of the browsing process. Rice et al. [17] also considered serendipity as something interesting or unexpectedly found during information browsing. Agarwal [6] also posited that information encountering could happen at any point regardless of whether or not one was actively seeking something, which would be the case during Internet browsing. Erdelez et al. [18] also pointed out that people have more and more opportunities to encounter information, instead of actively seeking information, which highlights the significant influence of serendipity on information acquisition. Therefore, we think that users may lose the sense of the passage of time because they immerse themselves in the serendipitous discovery of interesting or useful information, which attracts their attention, resulting in the phenomenon of flow and prolonging their online usage time. The influence of serendipity on users' flow experience is another topic of this study.

Through the above two research topics, we propose another content arrangement suggestion for online video hosting services to prolong usage time. Rather than "guessing" what kind of videos users like through algorithms, it provides more heterogeneous information and links to arouses users' curiosity and stimulate users to discover serendipities, and then immerse themselves in interlocking linkages.

In the rest of this article, we review past research on the concepts of serendipity and flow in Section 2. In Section 3, based on McCay-Peet and Toms's summary of the antecedents that affect serendipity in the information environment, a research model for the relationship between serendipity, flow experience, and extended use time on the online video platform is proposed. Section 4 mainly explains the research materials and methods. Section 5 presents the research data collected in the questionnaire survey and discusses the results further to answer research questions. Finally, the article is summarized in Section 6 with conclusions and suggestions for future research and practical applications.

\section{Theoretical Background}

\subsection{Serendipity}

The term "Serendipity" is variously defined as a happy and accidental discovery of finding valuable things, which comes from the fairytale "The Three Princes of Serendip." Based on empirical studies, Makri, Blandford, Woods, Sharples, and Maxwell [19] argued that serendipity usually occurs in unexpected situations and arouses a sense of surprise due to its unexpected and valuable outputs. Many scientific discoveries have been attributed to serendipity [20]. Studies of serendipity have also been developing in different disciplines, such as the history of medicine, history of science, information systems, and others [16,20-22].

For library and information science, Bernier first defined the concept of serendipity as the fortuitous discovery of information [18]. Erdelez defined information encountering as accidental information discovery, which is similar to serendipity [23]. Studies in the library and information science have focused on the patterns and effects of serendipity when people were looking for information $[16,19,24,25]$.

Erdelez [23] defined information encountering as the accidental discovery of information when searching for other materials. She pointed out that people who often experience information encountering usually have certain personality traits, such as diverse interests, intense curiosity, and a willingness to explore. In this sense, information encountering would tend to occur during active purposeful searches for information, but it might not happen when one is not actively seeking 
something in particular. However, Agarwal [6] posited that information encountering could happen at any point whether a person was actively seeking something or not, which would apply during Internet browsing. In this era of high information availability, internet users can access sufficient information without actively seeking it, and can also have higher chances of encountering information. That is, they are more likely to find useful information unexpectedly.

An important research topic about serendipity in the information field is whether it is possible to improve the probability of serendipity by using a mechanism [19]. From the literal definition, serendipity is an unexpected result, which is difficult to find at will. However, some empirical studies have found that serendipity may change under specific influences in certain situations [25-27].

The antecedents of serendipity can be divided into internal personal factors and external environmental factors $[19,28]$. From the perspective of internal personal factors, previous studies have shown that a prepared mind has an important influence on serendipity $[16,21,25,29]$. It is generally believed that the prepared mind is based on experience or previous concerns about a particular matter. Further, Cunha, Clegg, and Mendonça [30] believe that open-minded, curious, and prepared people have more opportunities to obtain serendipity. Curiosity refers to a high degree of interest in the various kinds of information. An open-mind means our vision is not limited in specific areas. Relaxing physical and mental boundaries provides us with more opportunities for cross-domain contacts [19]. People with curiosity, open, and prepared mindedness will have a higher chance to have serendipity.

From the perspective of external environmental factors, environmental characteristics also have influences on serendipity [28]. For example, according to interdisciplinary interviews with experts, Foster and Ford [16] pointed out environmental characteristics (such as classification patterns of the library) play important roles in the occurrence of serendipity. Regarding digital environments, many online services try to create more chances for serendipity through the design of operating environments [28]. However, some scholars questioned that if it is only to stimulate serendipity from the external environment, users will miss the opportunity to discover unexpected value by themselves, so that users will not perceive serendipity $[19,21]$. Therefore, to strengthen their serendipity strategies will be a new direction to replace the direct design of serendipity in the digital environment [19]. Actually, hyperlinks provided by a wide range of heterogeneous web pages in the digital environment can be the easiest way to support serendipity strategy development. With the development of search algorithms, users can easily find the information they want; however, users often overlook that browsing is another way to obtain information, and it is a pleasant experience to find unexpectedly useful information in the browsing processes [19]. To enable serendipity while browsing, online video platforms should provide extensive and diverse hyperlinks for users so they can conduct explorations according to their interests. As Erdelez [31] suggested, the digital environment needs to make information easier to browse and encourage users' curiosity so they can explore more comprehensive information and increasing the opportunities for serendipity.

Accordingly, providing users with extensive hyperlinks and stimulating curiosity could increase the likelihood of serendipity. André and Schraefel [21] proposed that the environment must be designed to help users prepare for unexpected information links as much as possible and to help users understand the values of information links in different fields in various occasional opportunities. Therefore, McCay-Peet and Toms [28] proposed five factors that influence serendipity: induced curiosity, presented variety, enabled connections, triggered divergence, and introduced unexpected information for the design of digital environments. In this study, we will refer to these five factors to discuss the impacts of online video platform design on serendipity.

\subsection{The Flow Experience}

In past research, online games, online shopping, and computer-mediated communication were shown to be typical environments in which users experience flow [32]. Accordingly, this study suggests that browsing online video platforms will also attract users' attention and produce flow 
experiences that will affect their usage behavior. Therefore, we use the flow theory, as proposed by Csikszentmihalyi [33], to explore this effect and determine the method of measuring flow.

The original definition of flow is the overall feeling of people when they concentrate on their actions [33]. More precisely, Csikszentmihalyi [7] defined flow using three characteristics: an altered sense of time, a sense of control, and the merging of action and awareness. According to past research, the most popular elements of flow are autotelic experience, the merging of action and awareness, immediate feedback, distortion of temporal experience, concentration, and a sense of potential control [31].

Flow exists in various activities, such as artistic performances, writing, sports, works, and hobbies. In a computer-mediated environment, users also have flow experiences. Hoffman and Novak first applied the flow theory to these environments [8]. They believed that flow experience could provide a new research framework to understand user behavior in computer-mediated environments. Hoffman and Novak [8] proposed that flow experience occurs during navigation, which is characterized by something that is intrinsically enjoyable accompanied by self-reinforcement and a loss of self-consciousness. Their model proposed a three-layer architecture comprising the cause, the state, and the result of the influence of the online environment on flow $[8,9,13]$. Based on this model, researchers studied the flow in different online environments and found that the flow impact on the user attitudes of the website [34], the intention of using the website [35], the satisfaction with the website [36], the willingness to visit the website again [37], loyalty to the website [38], the intention to participate in online games [10], the intention to shop online [39], and the satisfaction and stickiness in AR games [32]. Therefore, this study infers that flow also has an impact on prolonging usage time in the online video platforms.

Previous studies have taken different approaches to measuring flow. In subsequent studies [9,13], Hoffman and Novak held that flow is a single state, and they adopted a simpler approach by describing it in a paragraph, and then, measured users' feelings according to three items. Following this concept, many studies have adopted this model to study flow $[10,15,37]$. However, some studies believed that flow experience is composed of multi-faceted feelings, and that it should be measured by constructing integrated scales based on the definition of flow. For example, Skadberg and Kimmel [14] used enjoyment and time distortion to measure users' flow state; Jiang and Benbasat [40] integrated control, attention, and enjoyment to measure the flow state. In addition, some other studies have suggested that flow is a loose concept, which shall be regarded as the main concept. Different sub-dimensions shall be measured separately according to their definitions, and then, their effects on flow are explained $[12,38,41]$. These methods of measuring flow can be divided into two categories: unidimensional and multi-dimensional [41], and both methods have their advantages. The advantage of unidimensional is that it is easy to explore the predecessor factors and the relationship between the flow experience itself and the subsequent factors. The advantage of multidimensional is that in-depth analysis of the various sub-dimensions of flow can provide a more comprehensive model of analysis for flow states [41]. Although there is controversy regarding the way to measure flow [41], this study adopts the unidimensional approach to integrate time distortion, curiosity, concentration, and enjoyment to measure the concept of flow to explore new factors affecting the flow.

\section{Conceptual Model and Hypotheses}

\subsection{Online Video Platform (Online Video Hosting Service)}

Online video platforms refer to the free storage space provided by online video service providers, which enables users to upload, share, and watch video content on the Internet. With the increase of network bandwidth and the development of streaming technology, online video services are becoming more and more popular. Websites providing online video streaming services, such as YouTube, Hulu, Dailymotion, and Netflix, have also attracted many viewers. The content sources are divided into two categories: one is videos produced by production companies, such as Netflix; the other is videos 
created by users, such as YouTube. The main issues discussed in this study are related to the diversity and heterogeneity of the films provided by the video platforms. Therefore, this study employed YouTube because of its rich content and hyperlinks intended to stimulate and satisfy user curiosity.

\subsection{The Antecedents of Perceived Serendipity}

The external environment is an important context influencing serendipity. Erdelez [31] suggested that digital information should be easy to browse and the digital environment should provide functionality for users to explore with curiosity. Toms [25] proposed that digital information environment should arouse users' curiosity and urge them to explore, so that they may have serendipitous discoveries. This means that online video platforms provide environments conducive to people's experiences of serendipity.

Therefore, the interface properties provided by the video platform could be factors for predicting serendipity. Based on the research of Björneborn [42] regarding physical libraries, McCay-Peet and Toms [28] summarized the original ten factors into five factors supporting serendipity in digital environments: induced curiosity, presented variety, enabled connections, triggered divergence, and introduced unexpected information. "Enabled connections" refers to the connection between different topics that can be provided by the system to enable users to explore or browse between different topics. "Introduced unexpected information" refers to the system's provision of unexpected or novel information for users. "Presented variety" refers to the system's provision of extensive and diverse content for users to explore or browse information. "Triggered divergence" means that the system proposes different ways to trigger the user's association, in order to facilitate serendipity. "Induced curiosity" means that the environment and information provided by the system can trigger the user's curiosity to explore serendipity.

Regarding the five factors related to the digital environment, and according to the research results of McCay-Peet and Toms [28], the order of significance of the factors influencing serendipity is: enabled connections, introduced the unexpected information, presented variety, triggered divergence, and induced curiosity. According to Makri et al. [19], it is crucial to enhance users' serendipity strategies rather than designing serendipity directly. We think that enabled connections, introduced unexpected information, and induced curiosity are three critical factors that may affect users' serendipity in the design of video platform environments. Because user-generated content is inherently diverse and heterogeneous, the presented variety has been included in the control variable when selecting the research target: YouTube. The triggered divergence involves users' characteristics and experience, as well as subjective judgment, which is difficult to measure. Therefore, we do not discuss these two factors in this study.

In the Internet environment, users rarely have clear goals when browsing, and they are often attracted to new topics and content. Makri et al. [19] suggested that browsing the Internet is a joyful experience for users, particularly when they discover useful information unexpectedly. They also pointed out that serendipity might be supported simply by providing hyperlinks across loosely related webpages. When social media provides hyperlinks across topics and content, users can easily reach their targets. We believe that the hyperlinks can make it easy for users to link to different topics, and provide users with recommended links to various topics, which conforms to the factor of enabled connections. Therefore, we propose the following hypothesis:

Hypothesis (H1). Enable connections positively relates to perceived serendipity while browsing on YouTube.

In addition to recommending videos through algorithms based on user's browsing records, online video platforms also provide different categories of popular videos for users. The popularity of videos depends on the number of views by the overall users, rather than prediction through algorithms of videos that users may be interested in, which can avoid the filter bubble. In other words, a personalized search algorithm might exclude information unrelated to users and make users ignore some serendipitous information when searching. Therefore, we believe that the classification can 
provide users with extensive and diverse information, as well as a lot of unexpected information through popular videos and the recommendations of other users, which conforms to the factor of introduced unexpected information. Therefore, we propose the following hypothesis:

Hypothesis (H2). Introduced unexpected information positively relates to perceived serendipity while browsing on YouTube.

The information provided by a video platform includes titles, screenshots, and text descriptions; moreover, such information is included in user-generated content. For users, the diversity and heterogeneity of user-generated content can arouse the curiosity of different types of users, making them willing to view the content during their browsing process. When people visit YouTube, they browse content looking for items of interest, which is one method of information retrieval. Information retrieval is an interactive process between information seekers and media [43]. Some information seekers' personality traits are categorized as being more likely to have serendipity, which Erdelez [44] proposed are diverse interests, intense curiosity, and a willingness to explore. Agarwal [6] pointed out that the informational needs of the information seeker are based on the task at hand and the seeker's curiosity. McCay-Peet and Toms [45] also pointed out that openness is an internal factor that might facilitate serendipity, and they defined openness as a curiosity to experiences. Based on these previous studies, curiosity is an important characteristic that facilitates serendipity, and induced curiosity is another important factor for information systems. Therefore, we propose the following hypothesis:

Hypothesis (H3). Induced curiosity positively relates to perceived serendipity while browsing on YouTube.

In addition, curiosity is one of the main flow characteristics [35,38]. Especially for online activities, many studies believed that flow experience is related to curiosity. This is because the amount of information available online is more abundant than offline, and it is easy to find new information online that may trigger curiosity [34]. Thus, this study includes curiosity in the items for measuring the flow experience. Therefore, we infer that, if the digital environment has the characteristics of arousing curiosity, it may influence users' serendipity, and directly affect users entering the flow experience. Therefore, we propose the following hypothesis:

Hypothesis (H4). Induced curiosity positively relates to flow experience while browsing on YouTube.

\subsection{Perceived Serendipity, Flow Experience, and Prolonged Usage Time}

When users perceive serendipity, they will have a sense of happiness. Novak, Hoffman, and Yung [9] defined that the flow experience in a digital environment contains intrinsic pleasure and enjoyment; enjoyment was also regarded as one of the characteristics that constitute flow $[39,46]$. It has also been verified that the pleasure will influence users' subsequent behavior, such as their intention to revisit the website [39], and their intention to repurchase the website's goods [46]. From the above, we infer when users have serendipity in the digital environment, they will feel happy. If users continuously experience surprise and pleasure brought about by serendipity, their curiosity will be satisfied and they will have intrinsic pleasure, while linking to different information. Furthermore, they may be unaware of the passage of time and be immersed in the online video platform, thus, entering the flow experience and prolonging their usage time. Sometimes, users enter the flow experience and are unaware of the passage of time; however, this does not always happen, although they still tend to follow the hyperlinks toward a serendipitous event. Users tend to pay attention to information and experience time distortion, which involuntarily and unconsciously prolongs their usage time; this is one reason why people are willing to continue certain activities [7]. Hence, the following hypotheses are proposed:

Hypothesis (H5). Perceived serendipity positively relates to experiencing the flow experience while browsing on YouTube. 
Hypothesis (H6). Perceived serendipity positively relates to the intention to prolong usage time while browsing on YouTube.

Hypothesis (H7). The flow experience positively relates to the intention to prolong usage time while when browsing on YouTube.

This study starts with the research motivation and proceeds to the final research conclusion, as shown in the research flow of Figure 1. Figure 2 presents the conceptual model. The model hypothesizes that flow experience and perceived serendipity are critical influences on intention to prolong usage time. At the same time, enabled connections, introduced unexpected information, and induced curiosity are hypothesized to influence perceived serendipity, and induced curiosity is also speculated to influence the flow experience. Perceived serendipity is also expected to affect the flow experience directly.

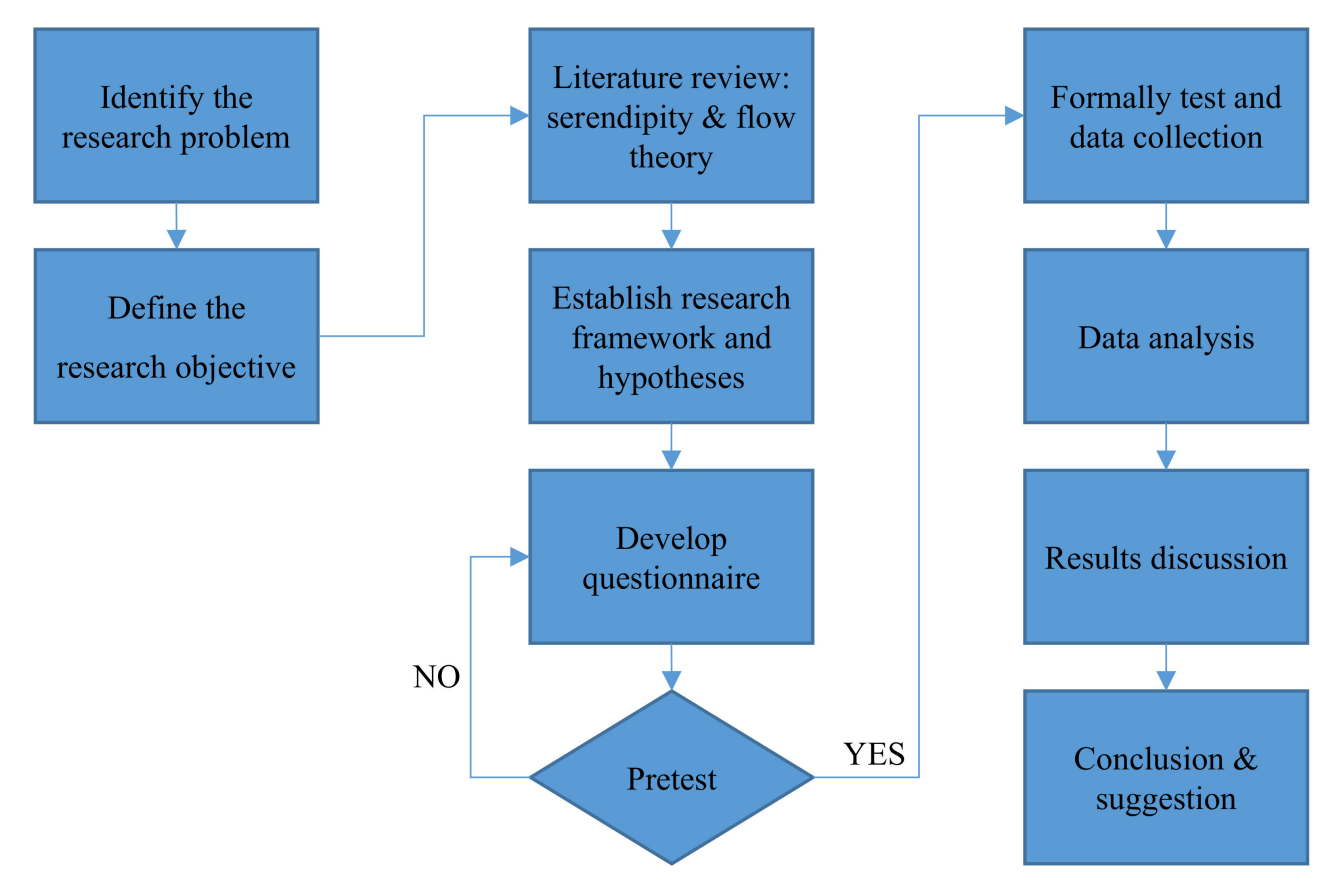

Figure 1. Research flow diagram.

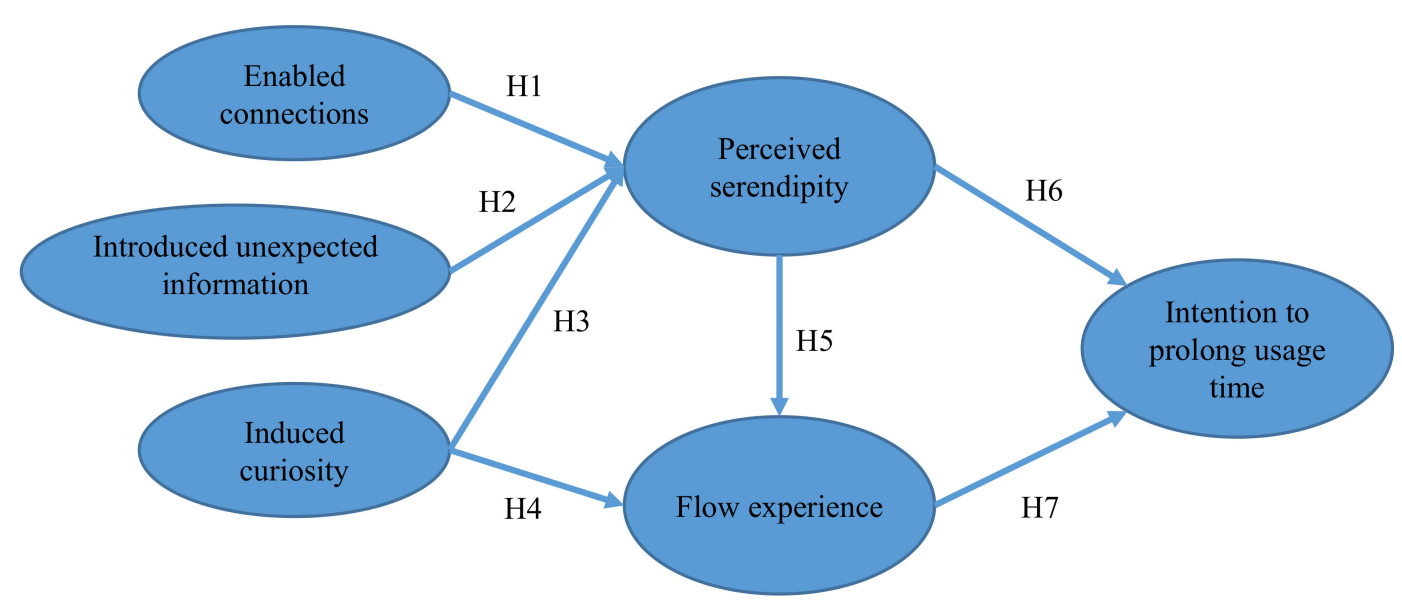

Figure 2. Conceptual model. 


\section{Materials and Methods}

\subsection{Sample and Data Collection}

The sample was comprised of 475 undergraduate students at two universities in Taiwan. The respondents completed paper questionnaires, of which 70 were dropped from analysis due to missing data, yielding 405 valid questionnaires. The SPSS 18.0 statistical software (IBM, Armonk, NY, USA) was used for descriptive statistics, and SPSS Amos 20 (IBM, Armonk, NY, USA) was used to test the hypotheses and research model.

\subsection{Questionnaire Design}

The concepts and questionnaire items were adjusted from previous studies (Table 1), and the list of items is shown in Appendix A. All items offered response options on a five-point Likert-type scale, ranging from 1 (strongly disagree) to 5 (strongly agree). The first version of the questionnaire was assessed and revised by three experts, and then, it was pre-tested to avoid ambiguity in the wording by 29 graduate students with experience browsing YouTube. Based on the respondents' feedback, several items were modified to clarify meaning. The reliability of all items was satisfactory (Cronbach's alpha $>0.80$ ), and all items appropriately loaded in confirmatory factor analysis (loadings $\geq 0.60$ ). Therefore, the survey instrument was confirmed to be valid and reliable.

Table 1. Operational definitions.

\begin{tabular}{ccc}
\hline Variable & Operational Definition & Reference \\
\hline Enabled connections (EC) & $\begin{array}{c}\text { YouTube provides connections } \\
\text { between topics and allows users to } \\
\text { explore or browse across topics. }\end{array}$ & McCay-Peet and Toms [28] \\
\hline $\begin{array}{c}\text { Introduced unexpected } \\
\text { information (IU) }\end{array}$ & $\begin{array}{c}\text { YouTube allows users to encounter } \\
\text { unexpected topics or provides content } \\
\text { that users do not normally explore. }\end{array}$ & McCay-Peet and Toms [28] \\
\hline Induced curiosity (IC) & $\begin{array}{c}\text { The topics or contents on YouTube } \\
\text { trigger the curiosity of users for } \\
\text { deeper exploration. }\end{array}$ & McCay-Peet and Toms [28] \\
\hline Perceived serendipity (PS) & $\begin{array}{c}\text { A personally surprising accidental } \\
\text { finding of useful or interesting } \\
\text { information while browsing YouTube }\end{array}$ & $\begin{array}{c}\text { Erdelez [31]; McCay-Peet and } \\
\text { Toms [45] }\end{array}$ \\
\hline Flow experience (FE) & $\begin{array}{c}\text { Immersion in browsing activity on } \\
\text { YouTube with a sense of time } \\
\text { distortion, curiosity, concentration, } \\
\text { and enjoyment }\end{array}$ & $\begin{array}{c}\text { Hoffman and Novak [8]; } \\
\text { Csikszentmihalyi [7] }\end{array}$ \\
\hline Intention to prolonged usage \\
time (PUT)
\end{tabular}$\quad$\begin{tabular}{c} 
Intention to continue using YouTube \\
\hline
\end{tabular}

\subsection{Descriptive Statistics}

In the sample, $63.46 \%$ of the respondents were female, and $36.54 \%$ were male. As undergraduate students were the respondents, the ages mostly ranged between 18 and 30 years old (76.30\%). More than three-quarters of the sample reported more than three years of YouTube experience, indicating adequate familiarity with YouTube. Regarding the frequency of use, more than half $(51.36 \%)$ were using the website daily, and the average daily usage time was between $30 \mathrm{~min}$ and one hour. Table 2 summarizes the sample's characteristics. 
Table 2. Sample characteristics $(n=405)$.

\begin{tabular}{|c|c|c|c|}
\hline Variable & Value & Frequency (n) & Percentage $(\%)$ \\
\hline \multirow{2}{*}{ Gender } & Male & 148 & 36.54 \\
\hline & Female & 257 & 63.46 \\
\hline \multirow{2}{*}{ Age (in years) } & $<20$ & 80 & 19.75 \\
\hline & $21-30$ & 325 & 80.25 \\
\hline \multirow{5}{*}{$\begin{array}{l}\text { YouTube usage } \\
\text { experience } \\
\text { (in years) }\end{array}$} & $<0.5$ & 10 & 2.47 \\
\hline & $0.5-1.0$ & 11 & 2.72 \\
\hline & $1.0-2.0$ & 26 & 6.42 \\
\hline & $2.0-3.0$ & 49 & 12.10 \\
\hline & $>3.0$ & 309 & 76.30 \\
\hline \multirow{5}{*}{$\begin{array}{l}\text { YouTube usage } \\
\text { frequency }\end{array}$} & Daily & 208 & 51.36 \\
\hline & $\begin{array}{l}\text { Several times per week } \\
\text { (but not every day) }\end{array}$ & 156 & 38.52 \\
\hline & Once per week & 21 & 5.19 \\
\hline & 2-3 times per month & 13 & 3.21 \\
\hline & Less than once per month & 7 & 1.73 \\
\hline \multirow{5}{*}{$\begin{array}{l}\text { Average usage time on } \\
\text { YouTube (hours) }\end{array}$} & $<0.5$ & 62 & 15.31 \\
\hline & $0.5-1.0$ & 169 & 41.73 \\
\hline & $1.0-2.0$ & 93 & 22.96 \\
\hline & $2.0-3.0$ & 48 & 11.85 \\
\hline & $>3.0$ & 33 & 8.15 \\
\hline
\end{tabular}

\section{Results}

\subsection{Tests of the Measurement Model}

Confirmatory factor analyses tested the measurement model. Table 3 shows that all of the appropriate indices exceeded the recommended standards, which demonstrates adequate fit [47].

Table 3. Fit indices.

\begin{tabular}{ccc}
\hline Fit Indices & Recommended Standard & Measurement Model \\
\hline$\chi$ 2/df & $\leq 3$ & 2.513 \\
Goodness of fit index (GFI) & $\geq 0.9$ & 0.898 \\
Adjusted for degrees of freedom (AGFI) & $\geq 0.8$ & 0.866 \\
Normed fit index (NFI) & $\geq 0.9$ & 0.907 \\
Non-normed fit index (NNFI) & $\geq 0.9$ & 0.927 \\
Comparative fit index (CFI) & $\geq 0.9$ & 0.938 \\
Root mean square error of approximation (RMSEA) & $\leq 0.08$ & 0.065 \\
Standard root mean square residual (SRMR) & $\leq 0.08$ & 0.0553
\end{tabular}

Reliability was evaluated using Cronbach's alpha and composite reliability to determine the internal consistency of the model. The Cronbach's alpha statistics ranged from 0.703 to 0.893 , which exceed the standard cutoff of 0.70 , as recommended by Nunnally [48]. The composite reliabilities are greater than 0.70 , as suggested by Fornell and Larcker [49]. Thus, the reliability and stability of the constructs are acceptable. Convergent validity was tested by using three statistical methods [50]: first, the values of item factor loadings should exceed 0.50; second, composite reliability should exceed 0.70; third, the minimum average variance extracted value of the constructs is 0.50 . Table 4 shows all of these 
test results, for which the factor loadings all exceed 0.50 . The constructs' composite reliabilities range from 0.703 to 0.893 , and the average variances extracted range from 0.536 to 0.680 ; therefore, all the aforementioned statistical tests confirmed the internal consistency of the constructs, which ensures convergent validity.

Table 4. Results of convergent validity statistical tests.

\begin{tabular}{|c|c|c|c|c|c|}
\hline Construct & Item & $\begin{array}{l}\text { Factor } \\
\text { Loading }\end{array}$ & $\begin{array}{l}\text { Cronbach's } \\
\text { Alpha }(\alpha)\end{array}$ & $\begin{array}{l}\text { Composite } \\
\text { Reliability }\end{array}$ & $\begin{array}{l}\text { Average } \\
\text { Variance } \\
\text { Extracted }\end{array}$ \\
\hline \multirow{2}{*}{ Induced curiosity (IC) } & IC01 & 0.804 & \multirow{2}{*}{0.785} & \multirow{2}{*}{0.784} & \multirow{2}{*}{0.644} \\
\hline & IC02 & 0.801 & & & \\
\hline \multirow{2}{*}{$\begin{array}{l}\text { Introduced unexpected } \\
\text { information (IU) }\end{array}$} & IU01 & 0.689 & \multirow{2}{*}{0.703} & \multirow{2}{*}{0.711} & \multirow{2}{*}{0.553} \\
\hline & IU02 & 0.794 & & & \\
\hline \multirow{4}{*}{ Enabled connections (EC) } & EC01 & 0.749 & \multirow{4}{*}{0.821} & \multirow{4}{*}{0.822} & \multirow{4}{*}{0.536} \\
\hline & $\mathrm{EC} 02$ & 0.732 & & & \\
\hline & EC03 & 0.746 & & & \\
\hline & EC04 & 0.699 & & & \\
\hline \multirow{4}{*}{ Perceived serendipity (PS) } & SS01 & 0.745 & \multirow{4}{*}{0.870} & \multirow{4}{*}{0.870} & \multirow{4}{*}{0.627} \\
\hline & SS02 & 0.774 & & & \\
\hline & SS03 & 0.831 & & & \\
\hline & SS04 & 0.815 & & & \\
\hline \multirow{4}{*}{ Flow experience (FE) } & FE01 & 0.748 & \multirow{4}{*}{0.893} & \multirow{4}{*}{0.894} & \multirow{4}{*}{0.680} \\
\hline & FE 02 & 0.870 & & & \\
\hline & FE 03 & 0.835 & & & \\
\hline & FE 04 & 0.839 & & & \\
\hline \multirow{4}{*}{$\begin{array}{l}\text { Intention to prolong usage } \\
\text { time (PUT) }\end{array}$} & PUT01 & 0.662 & \multirow{4}{*}{0.832} & \multirow{4}{*}{0.837} & \multirow{4}{*}{0.564} \\
\hline & PUT02 & 0.831 & & & \\
\hline & PUT03 & 0.796 & & & \\
\hline & PUT04 & 0.702 & & & \\
\hline
\end{tabular}

For discriminant validity, the average variance extracted value of a construct should be greater than the other correlation coefficients of the construct [49]. The correlation coefficients between pairs of constructs should be weaker than the constructs' square roots of the average variance extracted. Table 5 shows the result of the discriminant validity statistical tests and this result suggests that all of the constructs are empirically distinct. In general, the tests of the convergence and discriminative validity of the measurement model were effective.

\subsection{Results of Hypothesis Tests}

The hypotheses illustrated in Figure 2 were tested. The indices of the structural model fit evidenced a good fit (Table 3 above). The structural equation model's path coefficients are shown in Figure 3. With the exception of $\mathrm{H} 3$, all of the hypotheses were supported. 
Table 5. Results of discriminant validity statistical tests.

\begin{tabular}{|c|c|c|c|c|c|c|}
\hline Construct & IC & IU & EC & PS & FE & PUT \\
\hline IC & 0.802 & & & & & \\
\hline IU & $0.526^{* *}$ & 0.743 & & & & \\
\hline $\mathrm{EC}$ & $0.565^{* *}$ & $0.396^{* *}$ & 0.732 & & & \\
\hline PS & $0.527^{* *}$ & $0.528 * *$ & $0.626^{* *}$ & 0.791 & & \\
\hline $\mathrm{FE}$ & $0.368^{* *}$ & $0.346^{* *}$ & $0.456^{* *}$ & $0.463^{* *}$ & 0.824 & \\
\hline PUT & $0.408^{* *}$ & $0.424 * *$ & $0.378^{* *}$ & $0.503^{* *}$ & $0.704^{* *}$ & 0.751 \\
\hline
\end{tabular}

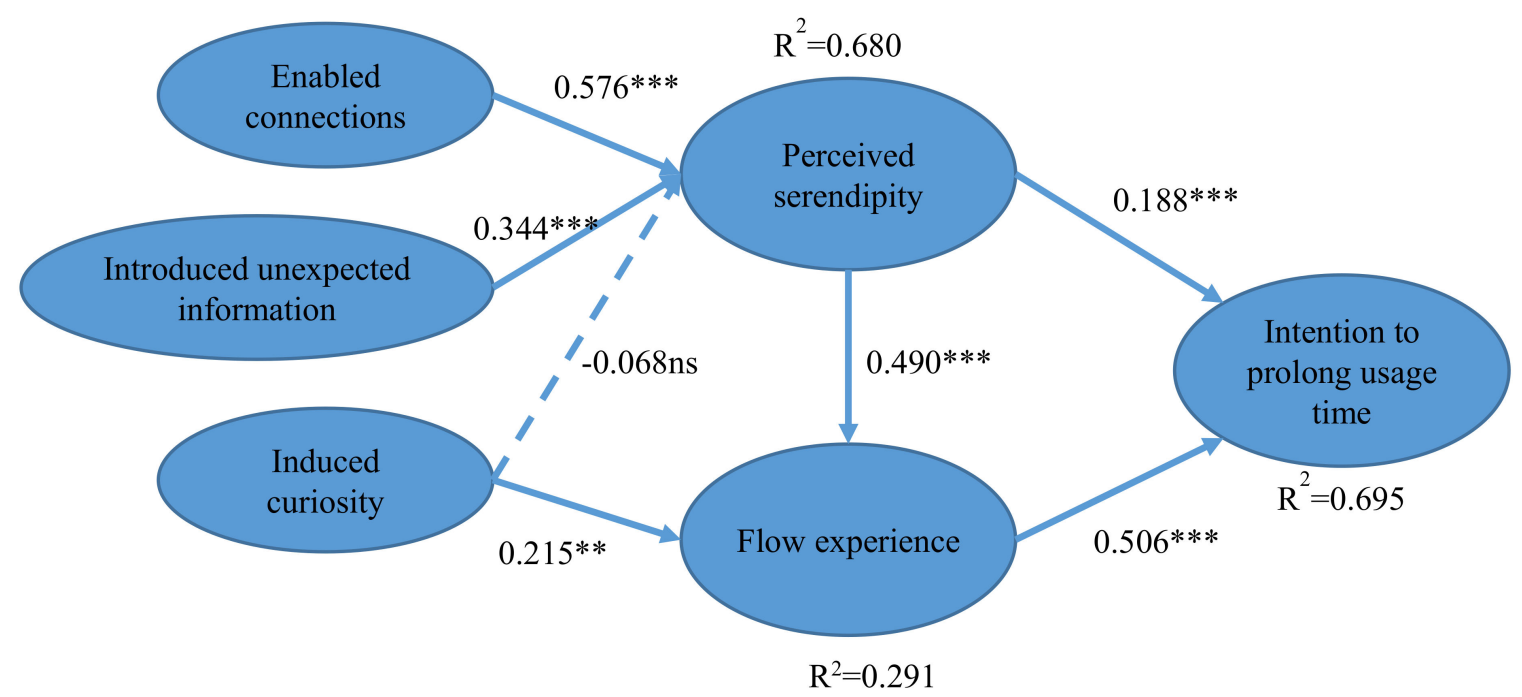

Figure 3. Structural equation model results of estimated beta $(\beta)$ values and coefficients of determination $\left(\mathrm{R}^{2}\right)(\mathrm{n}=405)\left({ }^{*}: p<0.05 ;{ }^{* *}: p<0.01 ;{ }^{* *}: p<0.001 ; \mathrm{ns}=\right.$ not significant $)$.

Regarding the factors of digital environment, enabled connections has a positive effect on perceived serendipity (H1: $\beta=0.576, p<0.001$ ), and introduced unexpected information has a positive effect on perceived serendipity ( $\mathrm{H} 2: \beta=0.344, p<0.001)$. However, while induced curiosity was not a statistically significant predictor of perceived serendipity (H3: $\beta=-0.068, p>0.05$ ), it positively influences flow experience (H4: $\beta=0.215, p<0.01)$.

Perceived serendipity positively influences flow experience (H5: $\beta=0.490, p<0.001)$, and the intention to prolong usage time increased as the flow experience increased (H7: $\beta=0.506, p<0.001)$. Another influence on the intention to prolong usage time is perceived serendipity (H6: $\beta=0.188$, $p<0.001$ ), indicating that respondents who experience serendipity while browsing YouTube prolonged their time on the site without flow experience. Overall, the model explains about 69.5 percent of the variance regarding the intention to prolong usage time, and Table 6 shows all hypothesis-testing results.

From Table 7, we know that the environmental factors provided by digital platforms have different effects on the intention to prolong usage time. Enabled connections have the highest overall effect on the intention to prolong usage time (0.251), followed by introduced unexpected information (0.150). Although induced curiosity has no significant impact on perceived serendipity in this study, it significantly affects the user's flow experience and then prolongs the usage time. Therefore, induced curiosity still has an indirect effect on the intention to prolong usage time (0.109), which is the lowest among the three environmental factors of digital platforms. 
Table 6. Hypothesis-testing results.

\begin{tabular}{lcc}
\hline \multicolumn{1}{c}{ Hypotheses } & $\beta$ & Result \\
\hline $\begin{array}{l}\text { H1: Enabled connections positively relates to perceived serendipity } \\
\text { while browsing on YouTube. }\end{array}$ & $0.576^{* * *}$ & Supported \\
\hline $\begin{array}{l}\text { H2: Introduced unexpected information positively relates to perceived } \\
\text { serendipity while browsing on YouTube. }\end{array}$ & $0.344^{* * *}$ & Supported \\
\hline $\begin{array}{l}\text { H3: Induced curiosity positively relates to perceived serendipity while } \\
\text { browsing on YouTube. }\end{array}$ & $-0.068 \mathrm{~ns}$ & Not supported \\
\hline $\begin{array}{l}\text { H4: Induced curiosity positively relates to flow experience while } \\
\text { browsing on YouTube. }\end{array}$ & $0.215^{* *}$ & Supported \\
\hline $\begin{array}{l}\text { H5: Perceived serendipity positively relates to experiencing the flow } \\
\text { experience while browsing on YouTube. }\end{array}$ & $0.490^{* * *}$ & Supported \\
\hline $\begin{array}{l}\text { H6: Perceived serendipity positively relates to intention to prolong } \\
\text { usage time while browsing on YouTube. }\end{array}$ & $0.188^{* * *}$ & Supported \\
\hline $\begin{array}{l}\text { H7: The flow experience positively relates to intention to prolong usage } \\
\text { time while browsing on YouTube. }\end{array}$ & $0.506^{* * *}$ & Supported \\
\hline \multicolumn{2}{c}{$p<0.05 ; * * p<0.01 ; * * * ;<0.001 ; n s=$ not significant. } &
\end{tabular}

Table 7. Analysis of direct and indirect effects.

\begin{tabular}{cccccccc}
\hline \multirow{2}{*}{ Construct } & \multicolumn{2}{c}{ PS } & \multicolumn{2}{c}{ FE } & \multicolumn{3}{c}{ PUT } \\
\cline { 2 - 9 } & Direct & Indirect & Direct & Indirect & Direct & Indirect & Total \\
\hline EC & 0.576 & - & - & 0.282 & - & 0.251 & 0.251 \\
\hline IU & 0.344 & - & - & & - & 0.150 & 0.150 \\
\hline IC & - & - & 0.215 & - & - & 0.109 & 0.109 \\
\hline PS & - & - & - & 0.490 & 0.188 & 0.248 & 0.436 \\
\hline FE & - & - & - & - & 0.506 & - & 0.431 \\
\hline$R^{2}$ & & 0.680 & & & 0.291 & & 0.695 \\
\end{tabular}

Some previous studies on flow have found significant gender differences [12,51]; the model was therefore tested for gender differences using AMOS 20 Multiple-Group Analysis software to compare males $(n=148)$ to females $(n=257)$ regarding the hypothesized relationships. The fitting indices of the two groups were consistent with the standard values $\left(\chi^{2} / \mathrm{df}=2.055, \mathrm{GFI}=0.859, \mathrm{AGFI}=0.815\right.$, $\mathrm{NFI}=0.866, \mathrm{CFI}=0.926$, RMSEA $=0.051$, SRMR $=0.059)$, indicating the validity of testing the differences between males and females. Table 8 (left columns) presents the results of the estimated model on the entire sample and by gender for the standardized coefficients $(\beta)$ and the Coefficients of Determination $\left(\mathrm{R}^{2}\right)$. Judging from the comparison of the path analysis of the two groups, the z-score of each path failed to reach the significant level, which means there was no significant difference in the paths between the two groups. Therefore, there was no difference between males and females in the exploration of video platforms found in this study.

Usage frequency is another way to learn about hypothesized relationships. For daily users, browsing YouTube is habitual, while non-daily users might be more likely to be irregularly seeking information. The indices of fit of these groups (208 daily users and 197 non-daily users) are consistent with the standard values $\left(\chi^{2} / \mathrm{df}=1.992, \mathrm{GFI}=0.859, \mathrm{AGFI}=0.815, \mathrm{NFI}=0.868, \mathrm{CFI}=0.929\right.$, RMSEA $=0.05$, SRMR $=0.063$ ). Table 8 (right columns) shows the comparative results, which indicate significant differences of usage frequency in the path from (1) IU to PS, (2) IC to FE, and (3) PS to FE. In the path from IU to PS, while both groups have significant influence, the strength of the influence of the two groups has a significant difference. This difference represents that the strength of the influence of IU on daily users' perception of serendipity is greater than that of non-daily users. In other words, 
daily users are more likely to be influenced by the unexpected movies provided by the platform, which results in serendipity. The influence of IC to FE is significant in daily users, but not in non-daily users. This finding indicates that daily users' curiosities will be intrigued by video titles, descriptions, and screenshots, making them enter the flow experience, while non-daily users will not enter the flow experience even after their curiosities are triggered. The last difference is that on the path from PS to $\mathrm{FE}$, the intensity of non-daily users is significantly higher than the daily users. This finding shows that it is easier for non-daily users to enter the flow experience than for daily users if they perceive serendipity, although they may not enter the flow experience through curiosity.

Table 8. Results of hypothesis tests on the entire sample $(n=405)$, by gender (males $=148$ and females $=257$, and by usage frequency (daily $=208$ and non-daily $=197)$.

\begin{tabular}{|c|c|c|c|c|c|c|c|}
\hline \multirow{3}{*}{ Hypothesis } & \multirow{3}{*}{$\begin{array}{c}\text { Entire } \\
\text { Sample }\end{array}$} & \multicolumn{3}{|c|}{ Gender } & \multicolumn{3}{|c|}{ Usage Frequency } \\
\hline & & Male & Female & & Daily & Non-Daily & \\
\hline & & $\beta$ & $\beta$ & z-Score & $\beta$ & $\beta$ & z-Score \\
\hline $\mathrm{H} 1: \mathrm{EC} \rightarrow \mathrm{PS}$ & $0.576^{* * *}$ & $0.399 * *$ & $0.679 * * *$ & 1.547 & $0.593^{* * *}$ & $0.482 * * *$ & -0.609 \\
\hline $\mathrm{H} 2: \mathrm{IU} \rightarrow \mathrm{PS}$ & $0.344^{* * *}$ & $0.348^{* *}$ & $0.355^{* * *}$ & -0.084 & $0.532 * * *$ & $0.196^{* *}$ & $-2.217 *$ \\
\hline H3: IC $\rightarrow$ PS & -0.068 & 0.040 & -0.093 & -0.717 & -0.150 & 0.001 & 0.812 \\
\hline $\mathrm{H} 4: \mathrm{IC} \rightarrow \mathrm{FE}$ & $0.215^{* *}$ & 0.244 & 0.200 * & -0.279 & $0.420^{* * *}$ & 0.046 & -2.395 * \\
\hline $\mathrm{H} 5: \mathrm{PS} \rightarrow \mathrm{FE}$ & $0.490^{* * *}$ & $0.664^{* * *}$ & $0.366^{* *}$ & -1.541 & 0.268 * & $0.696^{* * *}$ & 2.104 * \\
\hline H6: PS $\rightarrow$ PUT & $0.118^{* * *}$ & $0.217^{* *}$ & $0.161 * *$ & -0.569 & $0.150^{* *}$ & $0.264^{* * *}$ & 1.202 \\
\hline H7: FE $\rightarrow$ PUT & $0.506^{* * *}$ & $0.527^{* * *}$ & $0.488^{* * *}$ & -0.397 & $0.581^{* * *}$ & $0.417^{* * *}$ & -1.788 \\
\hline R2: PS & 0.680 & 0.622 & 0.716 & & 0.776 & 0.568 & \\
\hline R2: FE & 0.291 & 0.483 & 0.190 & & 0.367 & 0.224 & \\
\hline R2: PUT & 0.695 & 0.769 & 0.640 & & 0.741 & 0.661 & \\
\hline
\end{tabular}

\section{Conclusions and Implications}

For the operators of online video platforms, the sustainability of platform operations depends on improving the stickiness of users to the platform. The current practice of online video platforms is to use algorithms to predict videos that users may be interested in and to continue to recommend similar videos. This approach limits the possibility for users to access different video sources with limited attention and time. When users perceive that the videos supported by the platform are more homogeneous, they may feel boring because they are too similar, thereby reducing willingness to watch videos on this platform. This is similar to in an ecosystem, where the fewer kinds of organisms are available, the less stable the ecosystem can be; therefore, we believe that increasing heterogeneity would help to improve the sustainability of online video platform operations. We can take an ecosystem perspective to think about how to increase the heterogeneity and diversity of videos. Through a wide range of hyperlinks, users can increase the possibility of encountering serendipities in this platform, and they may enter the state of flow under the circumstance of interlocking and prolonging the usage of time. Online video platforms can grasp users' limited attention and time in order to increase user stickiness. In addition to expanding the platform's profitability, this can also improve the effectiveness of word-of-mouth communication.

The purpose of this study was to investigate the intention to prolong usage time by examining the influences of perceived serendipity and experiencing the flow state on YouTube. The results of this study verify the factors of perceived serendipity in the digital environment and prove that users will have a flow experience because of serendipity. In addition, the results also confirm that the users will prolong their usage time in the online video platform due to serendipity and flow experience. Therefore, in conclusion, two types of implications were drawn. 


\subsection{Theoretical Implications}

First of all, the contribution of this research is mainly to provide new perspectives for the flow theory. Without clear goals, users will also have flow experience because of serendipities and interlocking situations during the process of browsing the Internet. Csikszentmihalyi [7] concludes that flow experience is an integration of clear objectives and responses, and previous studies assumed that people having flow experiences are spontaneous and purposeful to accomplish an interesting, but not too difficult, task and enter the situation of losing self-consciousness and the transformation of time during the period. However, this study hypothesized that non-specific activities, such as browsing, trigger flow experience because people are naturally curious about things they find interesting, primarily via serendipity, and they become immersed in them and lose the sense of the passage of time. This flow experience caused by serendipity is a common phenomenon among users of social media sites, such as YouTube. The results also validate that users will enter into flow experience because of serendipity through their browsing behavior in the online video platforms. Further analysis shows that in goal-oriented activities, such as sports and games, the matching of challenges and abilities will encourage participants to continue without feeling bored or feeling like engagement is too complicated. Participants are willing to improve their abilities to overcome the more difficult challenges so that they will enter the flow experience. We believe that this is an "interlocking" situation, which makes participants generate adhesion and willingness to continue to participate in the activities. This kind of interlocking situation also occurs in design activities, such as reading novels.

However, this interlocking situation can also happen during online browsing without clear goals. When online video platforms provide extensive and heterogeneous recommendations and hyperlinks, users will have more chances to discover serendipities during the browsing process, and then to achieve an interlocking situation. As browsing online videos may not have clear goals, users are driven by curiosity, which generates the emerging goals of the activity. Therefore, although online browsing behavior may not have specific goals, this study verifies that the provision of hyperlinks and recommendations can make users more likely to find unexpected interesting or valuable information. With the mechanism to induce users' curiosities, users are more willing to explore serendipitous information and enter into interlocking situations, thereby having flow experience and prolonging usage time on the platform.

Secondly, this study also validates the factors in the external digital environment that affect serendipity and flow, in which the linkages play an important role. This result echoes the influence order of digital environmental factors on serendipity proposed by McCay-Peet and Toms [28]. It also agrees with the suggestion of Marki et al. [19] that allows users to strengthen their serendipity strategies to replace the idea of designing serendipity directly. We suggest that providing users with extensive and diverse links and recommending heterogeneous topics can increase the possibility of finding serendipities in the process of browsing when they are exposed to different types of information.

\subsection{Managerial Implications}

The platform examined by this study is YouTube, and the implications of the results apply to it and to similar online video platforms. The results show that providing extensive and diverse linkages, recommending browsing types of video data not familiar to users, and arousing users' curiosity in various ways will help to retain users. It can increase the user's adhesion to the online video platform, and provide another sustainable development thinking for the operation. Online video platforms should consider designing guidance mechanisms that include keyword analyses so that publishers can choose information classifications and devise titles to attract users, which might encourage them to use the hyperlinks. In addition, hyperlinks added to video descriptions should link to relevant content, or "hashtag" functions could be inserted for publishers to add hyperlinks. These functions could provide users with more comfortable and exciting experiences while retrieving information, and might encourage their curiosity while browsing, which might increase the likelihood that they use hyperlinks for further information retrieval. Users might find additional information via hyperlinks, which would 
increase the likelihood of serendipity. With the increasing likelihood of serendipity occurring on the video platform, as well as induced curiosity, users will be more likely to have flow experience, which might ultimately prolong their usage time.

In addition, a platform should make strategic adjustments to provide different information for users with different usage frequencies. According to the results, although the impact is significant on user groups of different frequencies on the path from the introduction of unexpected information (IU) to perceived serendipity (PS), there is a significant difference between the two groups. We can infer that daily users are hedonic-oriented and mainly check if there are new videos available. They will be more interested in the videos recommended by the platform, and more willing to watch the different types of videos (including popular movies). Thus, daily users are more likely to have serendipity by viewing these different types of videos. On the other hand, non-daily users tend to be more utilitarian-oriented in visiting an online video platform, meaning they search with a purpose for the videos they want to watch, and may not be as interested in the videos recommended by the platform. Therefore, they are less likely to have serendipity. This result is similar to the impact of serendipity on relaxing shopping [52]. On the path from induced curiosity (IC) to flow experience (FE), there is a significant impact only on the daily user group. This suggest that daily users who are more hedonic-oriented are more likely to be curious about the relevant information of the video when browsing so that they enter the flow experience. For non-daily users who are more function-oriented, they mainly focus on searching for videos, and their curiosity is less likely to be aroused to enter the flow experience. However, from the path of perceived serendipity (PS) to flow experience (FE), if non-daily users perceive serendipity, they would enter the flow experience more likely than daily users. This difference implies that although daily users are more likely to have serendipity while browsing, they are accustomed to the experience. Perceived serendipity does not explain variation in the flow experience of this group. It is similar to activities with clear goals, such as playing video games, meaning that users would not go into flow experience if they perceive the activities are too easy, and they may feel bored. Online video platform operators should consider analyzing the browsing preferences of daily users and use that information to induce daily users' curiosity. On the other hand, they might consider offering heterogeneous information to increase non-daily users' opportunities to encounter a variety of information (and serendipity) and to stimulate curiosity and willingness to explore, which might increase the possibility of flow experience and prolong usage time.

In order to attract users to keep using online video services, various online video platforms have begun to adopt different methods to increase user stickiness. For example: YouTube provides advertising dividends to content creators, encourages them to create content and operate channels, and gives consumers the option to pay for subscriptions to ad-free services; Netflix collects members' 'preferences for watching videos as its operating policy, and produces original videos in addition to outsourced videos. Traditional film and television content providers, such as Disney and FOX, set up their video streaming platforms to provide their movies and TV shows to convert original loyal viewers into online subscription members. However, the above approaches can be adjusted. Due to a large number of UGC videos, video hosting platforms, such as YouTube and Dailymotion, need more effective links and classification methods. These methods can include allowing other users to add tags or referrals so that users can browse more easily and increase their opportunities of encountering serendipity through mass sharing. The market for online video platforms is in an era of expansion. Whether the service provider moves from content production to platform operation, or from platform operation to content production, the diversity of videos can meet the needs of different users. It can also increase the chance that members will accidentally find interesting videos on the platform, and extend their platform usage time. Increasing the diversity of videos requires the cooperation of content providers, which also involves the composition of the video streaming platform ecosystem. However, the sound development of an online video platform ecosystem requires end-users to be willing to continue to use the platform, because user attention and time are the primary targets that 
video platforms need to fight for. The result of this research is another way of thinking beyond the existing platform.

\subsection{Limitations and Future Research}

This study focuses on YouTube users' behaviors to explore the effects of serendipity on the flow experience. In spite of valuable discoveries and implications, this study has some limitations. First, there are implications based on the results of analyses of a sample of Taiwanese undergraduate students, which were mostly aged from 18 to 30 . Although some employed students were included, the results are limited in their generalizability to all Internet users. Future studies could build on these results by analyzing different personal characteristics and ages, which might make the study's utility more robust. Second, while this study investigated the effects of digital environments on perceived serendipity, other factors might relate to perceived serendipity as well, such as the prior knowledge of users. Researchers should consider qualitative interview methods to gain in-depth understandings of the behaviors of online media. Last, although YouTube was used in this study as being representative of online media, many other types of online media offer various ways for users to interact; therefore, this study's results could be verified and extended using different types of online media. Similarly, future studies should consider a comparison across online video platforms to obtain valuable results.

Author Contributions: Conceptualization, H.-P.L. and Y.-H.C.; methodology, H.-P.L. and Y.-H.C.; software, Y.-H.C..; validation, Y.-H.C.; formal analysis, Y.-H.C.; investigation, Y.-H.C.; resources, Y.-H.C.; data curation, Y.-H.C.; writing-original draft preparation, Y.-H.C.; writing-review and editing, H.-P.L. and Y.-H.C.; visualization, Y.-H.C.; supervision, H.-P.L.; project administration, H.-P.L.; funding acquisition, H.-P.L. All authors have read and agreed to the published version of the manuscript.

Funding: This research received no external funding.

Conflicts of Interest: The authors declare no conflict of interest.

\section{Appendix A Questionnaire}

Induced curiosity (IC)

IC01. I am curious about the interesting YouTube video titles and would like to watch them.

IC02. I am curious about the interesting YouTube video screenshots and would like to watch them. Introduced the unexpected information (IU)

IU01. I am interested in many topics that YouTube recommends to me which normally I do not examine.

IU02. I find something interesting on YouTube trending pages that have unexpected content.

Enabled connections (EC)

EC01. I think that YouTube offers many different kinds of worthwhile video links.

EC02. YouTube recommends a lot of related video links to me based on my viewing history.

EC03. YouTube makes it easy for me to search for video links that I want to watch.

EC04. The subscription service provided by YouTube allows me quickly to find worthwhile video links.

Perceived serendipity (PS)

PS01. I can often see unexpected contents in the YouTube videos that I am interested or helpful to me, and I have a feeling of surprise.

PS02. I am often surprised the YouTube recommended videos that I never found, and they were interesting and helpful to me.

PS03. I often find interesting and surprising information in the YouTube fever movies.

PS04. There is a lot of valuable information more than what I want to know in searching YouTube. Flow experience (FE)

FE01. I often lose track of time and immerse in browsing and watching YouTube.

FE02. I often concentrate and ignore other things when I browse and watch YouTube videos.

FE03. I often feel fascinated when I browse and watch YouTube videos. 
FE04. I am very dedicated and often feel a distorted sense of time when I browse and watch YouTube videos.

Intention to prolonged usage time (PUT)

PUT01. If time permitted, I often keep browsing and watching different videos when I use YouTube.

PUT02. I often keep browsing and watching different videos on YouTube until I am interrupted by other things.

PUT03. I don't want to do anything else when I am browsing and watching YouTube videos.

PUT04. I often want to keep watching recommendation videos when I am browsing YouTube.

\section{References}

1. Lanham, R.A. The Economics of Attention: Style and Substance in the Age of Information; University of Chicago Press: Chicago, IL, USA, 2006.

2. Chiang, H.-S.; Hsiao, K.-L. YouTube stickiness: The needs, personal, and environmental perspective. Internet Res. 2015, 25, 85-106. [CrossRef]

3. Zhao, W.; Wang, A.; Chen, Y. How to Maintain the Sustainable Development of a Business Platform: A Case Study of Pinduoduo Social Commerce Platform in China. Sustainability 2019, 11, 6337. [CrossRef]

4. Grange, C.; Benbasat, I.; Burton-Jones, A. With a Little Help from My Friends: Cultivating Serendipity in Online Shopping Environments. Inf. Manag. 2019, 56, 225-235. [CrossRef]

5. Iansiti, M.; Levien, R. Keystones and Dominators: Framing Operating and Technology Strategy in a Business Ecosystem; Harvard Business School: Boston, MA, USA, 2004; pp. 24-25.

6. Agarwal, N.K. Towards a definition of serendipity in information behaviour. Inf. Res. 2015, 20, 675. Available online: http://InformationR.net/ir/20-3/paper675.html (accessed on 5 December 2019).

7. Csikszentmihalyi, M. Flow and the Foundations of Positive Psychology; Springer Netherlands: Dordrecht, The Netherlands, 2014.

8. Hoffman, D.L.; Novak, T.P. Marketing in Hypermedia Computer-Mediated Environments: Conceptual Foundations. J. Mark. 1996, 60, 50. [CrossRef]

9. Novak, T.P.; Hoffman, D.L.; Yung, Y.-F. Measuring the Customer Experience in Online Environments: A Structural Modeling Approach. Mark. Sci. 2000, 19, 22-42. [CrossRef]

10. Hsu, C.L.; Lu, H.P. Why Do People Play On-Line Games? An Extended TAM with Social Influences and Flow Experience. Inf. Manag. 2004, 41, 853-868. [CrossRef]

11. Zhou, T.; Li, H.; Liu, Y. The Effect of Flow Experience on Mobile SNS Users' Loyalty. Ind. Mngmnt Data Syst. 2010, 110, 930-946. [CrossRef]

12. Chang, Y.P.; Zhu, D.H. The role of perceived social capital and flow experience in building users' continuance intention to social networking sites in China. Comput. Hum. Behav. 2012, 28, 995-1001. [CrossRef]

13. Novak, T.P.; Hoffman, D.L.; Duhachek, A. The influence of goal-directed and experiential activities on online flow experiences. J. Consum. Psychol. 2003, 13, 3-16. [CrossRef]

14. Skadberg, Y.X.; Kimmel, J.R. Visitors' flow experience while browsing a Web site: Its measurement, contributing factors and consequences. Comput. Hum. Behav. 2004, 20, 403-422. [CrossRef]

15. Pelet, J.É.; Ettis, S.; Cowart, K. Optimal experience of flow enhanced by telepresence: Evidence from social media use. Inf. Manag. 2017, 54, 115-128. [CrossRef]

16. Foster, A.; Ford, N. Serendipity and information seeking: An empirical study. J. Doc. 2003, 59, 321-340. [CrossRef]

17. Rice, R.E.; McCreadie, M.; Chang, S.J.L. Accessing and Browsing Information and Communication; MIT Press: Cambridge, MA, USA, 2001.

18. Erdelez, S.; Heinström, J.; Makri, S.; Björneborn, L.; Beheshti, J.; Toms, E.; Agarwal, N.K. Research perspectives on serendipity and information encountering. Proc. Assoc. Inf. Sci. Technol. 2016, 53, 1-5. [CrossRef]

19. Makri, S.; Blandford, A.; Woods, M.; Sharples, S.; Maxwell, D. "Making my own luck": Serendipity strategies and how to support them in digital information environments. J. Assoc. Inf. Sci. Technol. 2014, 65, 2179-2194. [CrossRef]

20. Roberts, R.M. Serendipity: Accidental Discoveries in Science; Wiley: New York, NY, USA, 1989.

21. Andre, M.; Schraefel, M.; Teevan, J.; Dumais, S. Designing for (un) serendipity. In Proceedings of the 7th ACM Creativity and Cognition Conference, Berkeley, CA, USA, 26-30 October 2009. 
22. Yi, C.; Jiang, Z.; Benbasat, I. Designing for Diagnosticity and Serendipity: An Investigation of Social Product-Search Mechanisms. Inf. Syst. Res. 2017, 28, 413-429. [CrossRef]

23. Erdelez, S. Information encountering: A conceptual framework for accidental information discovery. In Proceedings of an International Conference on Information Seeking in Context; Taylor Graham Publishing: London, UK, 1997; pp. 412-421.

24. Edward Foster, A.; Ellis, D. Serendipity and its study. J. Doc. 2014, 70, 1015-1038. [CrossRef]

25. Toms, E.G. Understanding and facilitating the browsing of electronic text. Int. J. Hum. Comput. Stud. 2000, 52, 423-452. [CrossRef]

26. Erdelez, S. Investigation of information encountering in the controlled research environment. Inf. Process. Manag. 2004, 40, 1013-1025. [CrossRef]

27. Toms, E.G.; McCay-Peet, L. Chance encounters in the digital library. In International Conference on Theory and Practice of Digital Libraries; Springer: Berlin/Heidelberg, Germany, 2009; pp. 192-202.

28. McCay-Peet, L.; Toms, E. Measuring the dimensions of serendipity in digital environments. Inf. Res. Int. Electron. J. 2011, 16, n3.

29. Makri, S.; Blandford, A. Coming across information serendipitously-Part 1: A process model. J. Doc. 2012, 68, 684-705. [CrossRef]

30. Cunha, M.P.; Clegg, S.R.; Mendonça, S. On serendipity and organizing. Eur. Manag. J. 2010, 28, 319-330. [CrossRef]

31. Erdelez, S. Information Encountering: An Exploration Beyond Information Seeking. Unpublished. Ph.D. Thesis, Syracuse University, Syracuse, NY, USA, 1995.

32. Lee, C.H.; Chiang, H.S.; Hsiao, K.L. What drives stickiness in location-based AR games? An examination of flow and satisfaction. Telemat. Inform. 2018, 35, 1958-1970. [CrossRef]

33. Csikszentmihalyi, M. Beyond Boredom and Anxiety; Jossey-Bass: San Francisco, CA, USA, 1975.

34. Huang, M.-H. Designing website attributes to induce experiential encounters. Comput. Hum. Behav. 2003, 19, 425-442. [CrossRef]

35. Agarwal, R.; Karahanna, E. Time flies when you're having fun: Cognitive absorption and beliefs about information technology usage. Mis Q. 2000, 24, 665-694. [CrossRef]

36. Deng, L.; Turner, D.E.; Gehling, R.; Prince, B. User experience, satisfaction, and continual usage intention of IT. Eur. J. Inf. Syst. 2010, 19, 60-75. [CrossRef]

37. Luna, D.; Peracchio, L.A.; de Juan, M.D. Cross-Cultural and Cognitive Aspects of Web Site Navigation. J. Acad. Mark. Sci. 2002, 30, 397-410. [CrossRef]

38. Siekpe, J.S. An examination of the multidimensionality of flow construct in a computer-mediated environment. J. Electron. Commer. Res. 2005, 6, 31.

39. Hausman, A.V.; Siekpe, J.S. The effect of web interface features on consumer online purchase intentions. J. Bus. Res. 2009, 62, 5-13. [CrossRef]

40. Jiang, Z.; Benbasat, I. Virtual Product Experience: Effects of Visual and Functional Control of Products on Perceived Diagnosticity and Flow in Electronic Shopping. J. Manag. Inf. Syst. 2004, 21, 111-147. [CrossRef]

41. Hoffman, D.L.; Novak, T.P. Flow Online: Lessons Learned and Future Prospects. J. Interact. Mark. 2009, 23, 23-34. [CrossRef]

42. Björneborn, L. Serendipity dimensions and users' information behaviour in the physical library interface. Inf. Res. 2008, 13, 13-14.

43. Foster, A.E. A Nonlinear Model of Information Seeking Behaviour. J. Am. Soc. Inf. Sci. Technol. 2004, 55, 228-237. [CrossRef]

44. Erdelez, S. Information Encountering. In Theories of Information Behaviour; Fisher, K.E., Erdelez, S., McKechnie, L.E.F., Eds.; Information Today Inc.: Medford, NJ, USA, 2005; pp. 179-184.

45. McCay-Peet, L.; Toms, E.G. Investigating serendipity: How it unfolds and what may influence it. J. Assoc. Inf. Sci. Technol. 2015, 66, 1463-1476. [CrossRef]

46. Ozkara, B.Y.; Ozmen, M.; Kim, J.W. Examining the effect of flow experience on online purchase: A novel approach to the flow theory based on hedonic and utilitarian value. J. Retail. Consum. Serv. 2017, 37, 119-131. [CrossRef]

47. Hair, J.F.; Anderson, R.E.; Tatham, R.L.; Black, W.C. Multivariate Data Analysis; Prentice Hall: London, UK, 1998.

48. Nunnally, J.C. Psychometric Theory, 2nd ed.; McGraw-Hill: New York, NY, USA, 1978. 
49. Fornell, C.; Larcker, D.F. Structural equation models with unobservable variables and measurement error: Algebra and statistics. J. Mark. Res. 1981, 18, 382-388. [CrossRef]

50. Bagozzi, R.P.; Yi, Y. On the evaluation of structural equation models. J. Acad. Mark. Sci. 1988, 16, 74-94. [CrossRef]

51. Rettie, R. An exploration of flow during Internet use. Internet Res. 2001, 11, 103-113. [CrossRef]

52. Akram, U.; Hui, P.; Khan, M.; Yan, C.; Akram, Z. Factors Affecting Online Impulse Buying: Evidence from Chinese Social Commerce Environment. Sustainability 2018, 10, 352. [CrossRef] 